\title{
Excitation and luminescence of rare earth-doped lead phosphate glasses
}

\author{
J. Pisarska $\cdot$ M. Sołtys $\cdot$ L. Żur $\cdot$ W. A. Pisarski $\cdot$ \\ C. K. Jayasankar
}

Received: 8 May 2013/Accepted: 15 January 2014/Published online: 16 March 2014

(c) The Author(s) 2014. This article is published with open access at Springerlink.com

\begin{abstract}
Excitation and luminescence properties of $\mathrm{Eu}^{3+}, \mathrm{Tb}^{3+}$ and $\mathrm{Er}^{3+}$ ions in lead phosphate glasses have been studied. From excitation spectra of $\mathrm{Eu}^{3+}$ ions, the electron-phonon coupling strength and phonon energy of the glass host were calculated and compared to that obtained by Raman spectroscopy. Main intense and longlived luminescence bands are related to the ${ }^{5} \mathrm{D}_{0}{ }^{-}{ }^{7} \mathrm{~F}_{2}$ (red) transition of $\mathrm{Eu}^{3+}$, the ${ }^{5} \mathrm{D}_{4}-{ }^{7} \mathrm{~F}_{5}$ (green) transition of $\mathrm{Tb}^{3+}$ and the ${ }^{4} \mathrm{I}_{13 / 2}{ }^{4} \mathrm{I}_{15 / 2}$ (near-infrared) transition of $\mathrm{Er}^{3+}$. The critical transfer distances, the donor-acceptor interaction parameters and the energy transfer probabilities were calculated using the fitting of the luminescence decay curves from ${ }^{5} \mathrm{D}_{0}\left(\mathrm{Eu}^{3+}\right),{ }^{5} \mathrm{D}_{4}\left(\mathrm{~Tb}^{3+}\right)$ and ${ }^{4} \mathrm{I}_{13 / 2}\left(\mathrm{Er}^{3+}\right)$ excited states. The energy transfer probabilities for $\mathrm{Eu}^{3+}\left({ }^{5} \mathrm{D}_{0}\right)$, $\mathrm{Tb}^{3+}\left({ }^{5} \mathrm{D}_{4}\right)$ and $\mathrm{Er}^{3+}\left({ }^{4} \mathrm{I}_{13 / 2}\right)$ are relatively small, which indicates low self-quenching luminescence of rare earth ions in lead phosphate glasses.
\end{abstract}

\section{Introduction}

Glass materials doped with rare earth ions are widely used mainly for near-infrared solid-state lasers [1-4], broadband optical amplifiers [5-8], up-conversion systems [9-11], optical temperature sensors [12] and optical coherence tomography [13]. The optically active rare earth ions play a crucial role in lighting technology and optical display fields

\footnotetext{
J. Pisarska $(\bowtie) \cdot$ M. Sołtys · L. Żur · W. A. Pisarski Institute of Chemistry, University of Silesia, Szkolna 9, 40-007 Katowice, Poland

e-mail: Joanna.Pisarska@us.edu.pl

C. K. Jayasankar

Department of Physics, Sri Venkateswara University, Tirupati 517 502, India
}

due to emission colors based on their $4 f-4 f$ intraconfigurational transitions. Among several amorphous materials doped with rare earths [14-23], oxide and oxyfluoride phosphates are promising laser hosts because they are able to accommodate higher content of rare earth ions and still remain amorphous in comparison with other glass systems. Their structural and optical properties were characterized using different spectroscopic techniques in relation to practical applications such as glass host source emitting visible light [24-30] or near-infrared radiation [31-33].

In contrast to lead-free phosphate glass systems, nearinfrared [34-39] and visible [40-45] luminescence investigations of rare earth-doped lead phosphate glasses are less documented in the literature. Based on thermal and spectroscopic parameters obtained for rare earth ions, it can be concluded that lead phosphate glasses present interesting thermo-optical [34-36] and nonlinear optical [37] properties. Large enhancement of second harmonic generation (SHG) in cerium-doped lead phosphate glass was also observed [46]. Generally, the incorporation of $\mathrm{PbO}$ to phosphate glasses increases refractive indices of the host, which is useful for fabrication of holey fibers. The observed shift in the absorption edge to higher energies with increasing $\mathrm{PbO}$ content indicates the suitability of these glasses for optical device applications and makes them a potential candidate for radiation protection devices [47].

Here, we present the excitation and luminescence spectra of selected rare earth ions in lead phosphate glasses. The optically active rare earth ions were limited to $\mathrm{Eu}^{3+}, \mathrm{Tb}^{3+}$ and $\mathrm{Er}^{3+}$. Trivalent europium and terbium ions in several glass matrices are known as two red and green primary color light sources, respectively. Our preliminary investigations indicate that lead-free phosphate glasses [29] and lead phosphate glasses [45] are promising red-emitting 
solid-state materials related to ${ }^{5} \mathrm{D}_{0}{ }^{-} \mathrm{F}_{2}$ transition of $\mathrm{Eu}^{3+}$, whereas quite efficient and long-lived green luminescence due to ${ }^{5} \mathrm{D}_{4}{ }^{7} \mathrm{~F}_{5}$ transition of $\mathrm{Tb}^{3+}$ ions in phosphate glass and glass fibers was detected under 483-nm excitation [48]. In contrast to Ln-doped glass systems $(\mathrm{Ln}=\mathrm{Eu}, \mathrm{Tb})$, glasses doped with $\mathrm{Er}^{3+}$ or codoped with $\mathrm{Er}^{3+}-\mathrm{Yb}^{3+}$ are studied mainly for near-infrared emission at the third telecommunication window [49]. The previously published work by Santos et al [38] indicates that intense broadband infrared luminescence at $1,530 \mathrm{~nm}$, corresponding to the main ${ }^{4} \mathrm{I}_{13 / 2}-{ }^{4} \mathrm{I}_{15 / 2}$ laser transition of $\mathrm{Er}^{3+}$ ions in lead phosphate glass, was observed under 800-nm excitation. Several radiative parameters were calculated based on the experimental absorption spectrum and the Judd-Ofelt theory. An analysis of several parameters such as luminescence linewidth and lifetime or stimulated emission cross section suggests that $\mathrm{Er}^{3+}$-doped $\mathrm{PbPO}_{4}$ glass may potentially be a useful material for developing optical devices.

The investigations into the excitation and luminescence properties of rare earth ions in glasses are essential to design optical devices such as solid-state lasers, color displays, up-converters and optical fiber amplifiers. In this work, the excitation and luminescence properties of $\mathrm{Eu}^{3+}$, $\mathrm{Tb}^{3+}$ and $\mathrm{Er}^{3+}$ ions in lead phosphate glasses are presented. From excitation spectra of $\mathrm{Eu}^{3+}$ ions, the electronphonon coupling strength and phonon energy of the glass host were calculated and compared to that obtained by Raman spectrum. The red-to-orange $\left(\mathrm{Eu}^{3+}\right)$ and green-toblue $\left(\mathrm{Tb}^{3+}\right)$ luminescence intensity ratios as well as the linewidths and measured lifetimes were determined based on luminescence spectra and their decays. The spectral characteristics of $\mathrm{Eu}^{3+}$ and $\mathrm{Tb}^{3+}$ ions in lead phosphate glasses are important from the optical point of view. These rare earth ions are still widely used particularly for red and green emission in modern solid-state lighting and display technology. In particular, the luminescence linewidth and measured lifetime were examined for the ${ }^{4} \mathrm{I}_{13 / 2}-{ }^{4} \mathrm{I}_{15 / 2}$ main NIR laser transition of $\mathrm{Er}^{3+}$, which is demanded for broadband optical amplifiers operating in the third telecommunication window. Theoretical calculations were also applied for luminescence decay curve analysis in order to obtain information about interactions between rare earth ions in lead phosphate glasses. The critical transfer distances, the donor-acceptor interaction parameters and the energy transfer probabilities were calculated. The knowledge of these values is necessary to evaluate self-quenching luminescence processes of rare earth ions in the studied glass system.

On the other hand, the $\mathrm{PbO}$ can form stable glasses and make them more moisture resistant because it plays a dual role: network modifier (ionic $\mathrm{Pb}-\mathrm{O}$ ) and network former (covalent $\mathrm{Pb}-\mathrm{O}$ ). Consequently, the luminescence properties of rare earth ions in lead phosphate glasses are strongly influenced by the presence of highly polarizable divalent $\mathrm{Pb}^{2+}$ ions due to the strong and direct nature of $\mathrm{Pb}-\mathrm{O}$ bonds. These phenomena were also observed for lead borate glasses [50, 51]. Because of the above facts, lead phosphate glasses are significant in the field of solid-state lasers.

\section{Experimental details}

Lead phosphate glasses with general formula $45 \mathrm{PbO}$ $45 \mathrm{P}_{2} \mathrm{O}_{5}-9.5 \mathrm{Ga}_{2} \mathrm{O}_{3}-0.5 \mathrm{Ln}_{2} \mathrm{O}_{3}$ (where $\mathrm{Ln}$ denotes $\mathrm{Eu}, \mathrm{Tb}$ or $\mathrm{Er})$ in mole percent (mol\%) were prepared by mixing and melting appropriate amounts of metal oxides of high purity ( $99.99 \%$, Aldrich Chemical Co.). The samples were prepared in a glove box. A homogeneous mixture was heated in a protective atmosphere of dried argon. In order to compare $\mathrm{OH}^{-}$content, the glass samples were also prepared in air. Mixed reagents were melted for $0.5 \mathrm{~h}$ at $T=1,100^{\circ} \mathrm{C}$.

The X-ray diffraction analysis (XRD) was used to confirm amorphous nature of the studied glass samples. XRD patterns were carried out using an INEL diffractometer. Fully amorphous lead phosphate glasses doped with $\mathrm{Eu}^{3+}$ and $\mathrm{Tb}^{3+}$, except $\mathrm{Er}^{3+}$, were fabricated in a glove box in order to eliminate hydroxyl groups and then examined using infrared spectroscopy. The FT-IR and Raman spectra were measured with a Bruker spectrometer using standard $\mathrm{KBr}$ disk techniques. From accumulated experience, it is known that the $\mathrm{OH}^{-}$content is considerably higher in phosphate glass than in other glass systems. These phenomena are associated with the more hygroscopic nature of $\mathrm{P}_{2} \mathrm{O}_{5}$. Our previous investigations clearly indicate that intensity of IR band due to vibration of $\mathrm{OH}^{-}$ groups is drastically lower for glass sample fabricated in a protective atmosphere of dried argon in glove box than traditionally in an air [45]. These effects are important from the optical point of view, because relatively high content of $\mathrm{OH}^{-}$groups effectively quenches luminescence from excited states of rare earth ions in phosphate-based glasses [52-56].

The excitation and emission spectra for $\mathrm{Eu}^{3+}$ and $\mathrm{Tb}^{3+}$ were measured with a Jobin Yvon Fluoromax4 spectrophotometer. Spectral resolution was $0.1 \mathrm{~nm}$. Luminescence decay curves with accuracy $2 \mu$ s were acquired. Nearinfrared emission spectra for $\mathrm{Er}^{3+}$ were measured using a Continuum Model Surelite I optical parametric oscillator pumped by a third harmonic of a Nd:YAG laser. Luminescence was dispersed by a 1-m double-grating monochromator. Emitted radiation was detected with an InGaAs TEC 900-2,200-nm detector. Emission spectra were collected using a Stanford SRS 250 boxcar integrator. Spectral resolution was $\pm 0.1 \mathrm{~nm}$. Luminescence decay curves were 
recorded and stored by a Tektronix TDS 3052 oscilloscope. Decay curves with accuracy of $\pm 2 \mu$ s were measured. All measurements were taken at room temperature.

\section{Results and discussion}

\subsection{Excitation}

Figure 1 presents excitation spectrum for $\mathrm{Eu}^{3+}$ ions in lead phosphate glass. Insets show phonon sideband of $\mathrm{Eu}^{3+}$ (PSB) located near $440 \mathrm{~nm}$ (on the right) and Raman spectrum recorded for the studied glass sample (on the left). Excitation spectrum for europium ions was recorded in $300-500 \mathrm{~nm}$ ranges monitored at $\lambda_{\mathrm{em}}=611 \mathrm{~nm}$ $\left({ }^{5} \mathrm{D}_{0}{ }^{-7} \mathrm{~F}_{2}\right.$ red transition of $\left.\mathrm{Eu}^{3+}\right)$. Several bands can be assigned to the transitions originating from the ${ }^{7} \mathrm{~F}_{0}$ ground state to the ${ }^{5} \mathrm{D}_{2},{ }^{5} \mathrm{D}_{3},{ }^{5} \mathrm{~L}_{6},{ }^{5} \mathrm{~L}_{7},{ }^{5} \mathrm{G}_{\mathrm{J}}$ and ${ }^{5} \mathrm{D}_{4}$ excited states of $\mathrm{Eu}^{3+}$. Phonon sideband (PSB) associated with the pure electronic transition (PET) of ${ }^{7} \mathrm{~F}_{0}-{ }^{5} \mathrm{D}_{2}$ at $463 \mathrm{~nm}$ is also clearly observed. Two important parameters, the electronphonon coupling strength $g$ and the phonon energy of the glass host $h \omega$, were determined from phonon sideband measurement. The electron-phonon coupling strength is the intensity ratio of the PSB, $\int I_{\mathrm{PSB}} \mathrm{d} v$, to the PET, $\int I_{\mathrm{PET}} \mathrm{d} v$, whereas the phonon energy is the difference between the position of the PSB and the one of the PET.

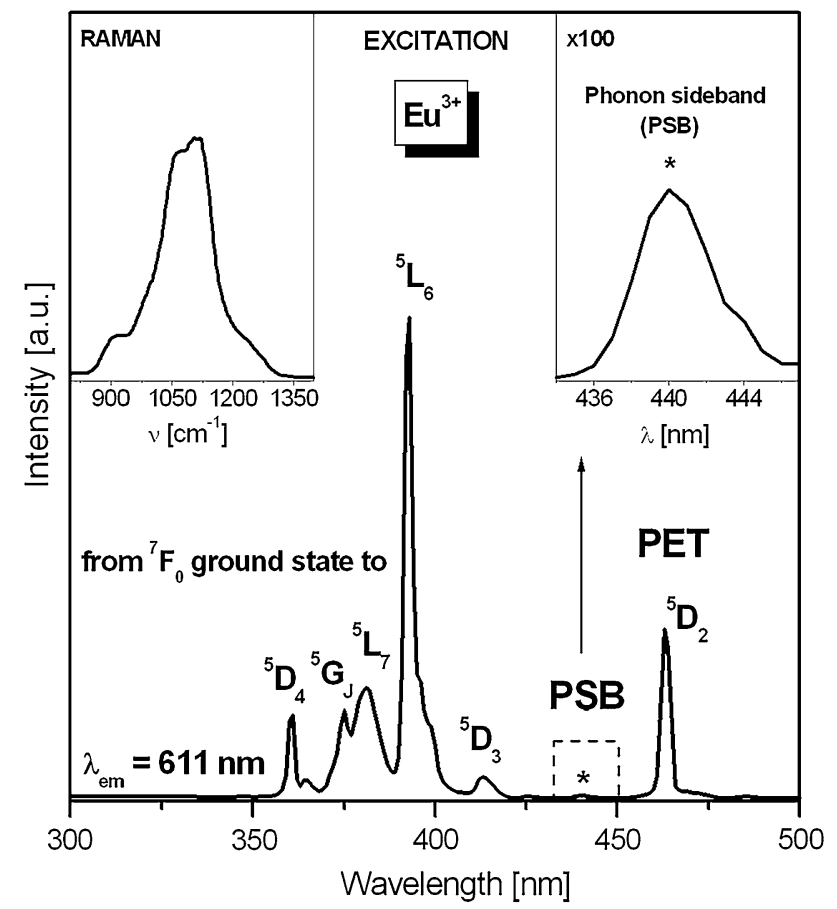

Fig. 1 Excitation spectrum for $\mathrm{Eu}^{3+}$ ions in lead phosphate glass. PSB and PET are indicated. Inset shows Raman spectrum detected for lead phosphate glass in $800-1,400 \mathrm{~cm}^{-1}$ frequency region $g=\frac{\int I_{\mathrm{PSB}} \mathrm{d} v}{\int I_{\mathrm{PET}} \mathrm{d} v}$

$h \omega=$ PSB - PET

Based on literature data [57], it is well known that the multiphonon relaxation rate, $W_{p}(T)$, depends on the electron-phonon coupling strength and phonon energy of the glass host using the following relations:

$W_{p}(T)=W_{0}(0) \exp (-\alpha \Delta E)$

$\alpha=\frac{\ln (p / g)-1}{h \omega}$

$p=\frac{\Delta E}{h \omega}$

where $p$ denotes the phonon number, $\Delta E$ the energy gap between neighboring energy states and $W_{0}(0)$ the transition probability extrapolated to zero energy gap, which is independent of the electronic nature of rare earth ions.

The nonradiative multiphonon relaxation rate is often given as $W_{p}(T) / W_{0}(0)$ [58]. The values of 1,750 and $2,500 \mathrm{~cm}^{-1}$ as the ${ }^{5} \mathrm{D}_{1}-{ }^{5} \mathrm{D}_{0}$ and ${ }^{5} \mathrm{D}_{2}-{ }^{5} \mathrm{D}_{1}$ energy gaps of $\mathrm{Eu}^{3+}$ ions are used for $W_{p}(T) / W_{0}(0)$ calculations. The parameters from phonon sideband measurement are summarized in Table 1. The energy phonon (PSB-PET) is in a good agreement with the value obtained from Raman spectrum. The electron-phonon coupling strength and nonradiative relaxation rate are consistent with the results obtained for similar oxyhalide phosphate glasses containing $\mathrm{Eu}^{3+}$ ions [58].

Figure 2 shows excitation spectrum for $\mathrm{Tb}^{3+}$ ions in lead phosphate glass in comparison with that obtained for previously studied lead borate glass. The excitation spectrum was monitored at $\lambda_{\mathrm{em}}=543 \mathrm{~nm}$, corresponding to the main ${ }^{5} \mathrm{D}_{4-}{ }^{7} \mathrm{~F}_{5}$ green transition of $\mathrm{Tb}^{3+}$. The observed bands can be assigned to transitions originating from the ${ }^{7} \mathrm{~F}_{6}$ ground state to the ${ }^{5} \mathrm{D}_{4},{ }^{5} \mathrm{D}_{3},{ }^{5} \mathrm{G}_{6},{ }^{5} \mathrm{~L}_{10},{ }^{5} \mathrm{G}_{5},{ }^{5} \mathrm{~L}_{9},{ }^{5} \mathrm{~L}_{8},{ }^{5} \mathrm{~L}_{7},{ }^{5} \mathrm{D}_{1},{ }^{5} \mathrm{H}_{7}$ and ${ }^{5} \mathrm{H}_{6}$ excited states of $\mathrm{Tb}^{3+}$ ions. In contrast to lead borate glass, the intensities of these transitions are relatively high. Independently of wavelength excitation, the high-lying excited states

Table 1 Parameters obtained from phonon sideband measurement

\begin{tabular}{ll}
\hline Parameters & $\mathrm{PbO}-\mathrm{P}_{2} \mathrm{O}_{5}$ glass host \\
\hline Energy phonon ${ }^{\mathrm{a}}\left(\mathrm{cm}^{-1}\right)$ & 1,120 \\
PSB-PET $^{\mathrm{b}}\left(\mathrm{cm}^{-1}\right)$ & 1,117 \\
Electron-phonon coupling strength $\mathrm{g}$ & 24 \\
$\quad\left(\times 10^{-3}\right)$ & \\
Nonradiative relaxation rate $W_{p}(T) /$ & $6.82 \times 10^{-3}\left(\right.$ from ${ }^{5} \mathrm{D}_{1}$ \\
$W_{0}(0)$ & state) \\
& $3.62 \times 10^{-4}\left(\right.$ from ${ }^{5} \mathrm{D}_{2}$ \\
& state) \\
\hline
\end{tabular}

\footnotetext{
a Value obtained from Raman spectrum

b Value obtained from excitation spectrum of $\mathrm{Eu}^{3+}$
} 


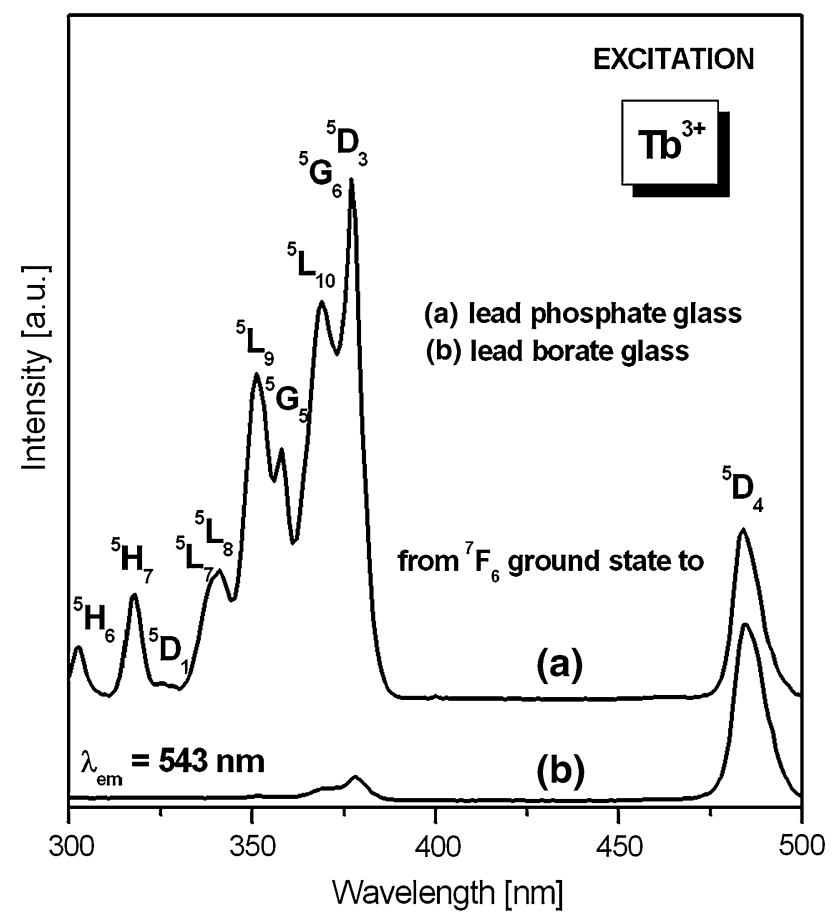

Fig. 2 Excitation spectrum for $\mathrm{Tb}^{3+}$ ions in lead phosphate glass. For comparison, spectrum for Tb-doped lead borate glass is also presented

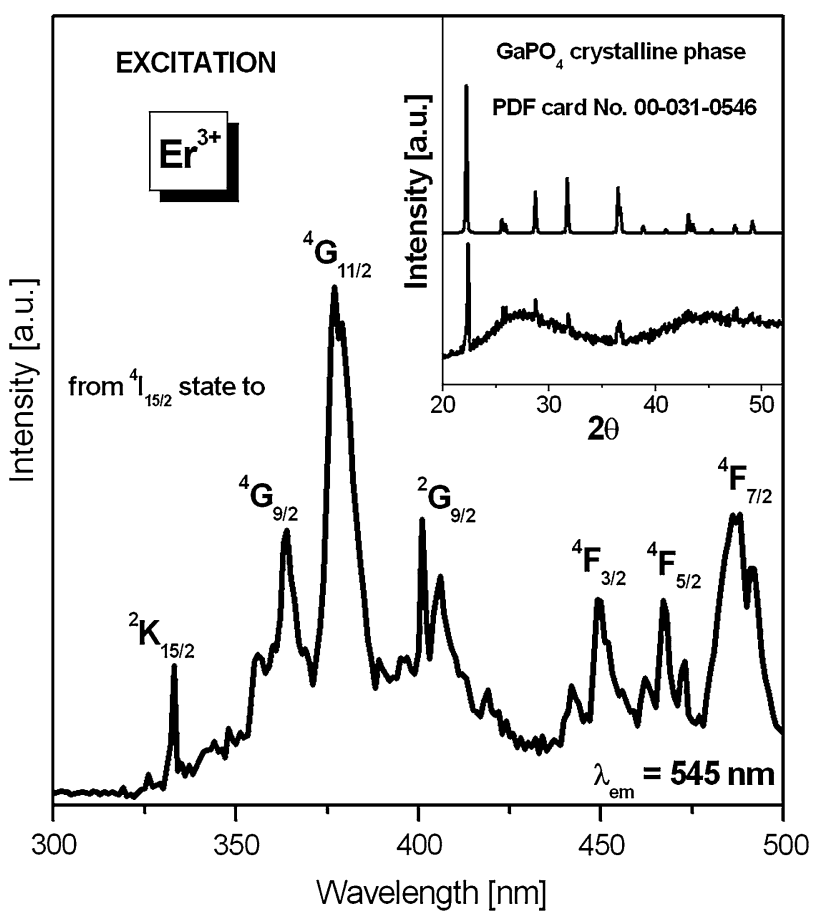

Fig. 3 Excitation spectrum for $\mathrm{Er}^{3+}$ ions in lead phosphate glass. Inset shows XRD pattern for semicrystalline Er-doped sample with $\mathrm{GaPO}_{4}$ phase

of $\mathrm{Tb}^{3+}$ ions in lead phosphate glass can be quite well populated under UV diode laser excitation. It suggests efficient pumping of terbium-doped lead phosphate glasses by commercially available UV laser sources, which consequently lead to the intense and long-lived green luminescence related to ${ }^{5} \mathrm{D}_{4-}{ }^{7} \mathrm{~F}_{5}$ transition of $\mathrm{Tb}^{3+}$.

Finally, the excitation spectrum for $\mathrm{Er}^{3+}$ ions in lead phosphate glass is presented in Fig. 3. The spectrum was monitored at $\lambda_{\mathrm{em}}=545 \mathrm{~nm}$, due to ${ }^{4} \mathrm{~S}_{3 / 2}{ }^{4} \mathrm{I}_{15 / 2}$ transition of $\mathrm{Er}^{3+}$. The Stark splitting has been well observed in this spectrum. Several narrowed and well-resolved bands are originating to transitions from the ${ }^{4} \mathrm{I}_{15 / 2}$ ground state to the ${ }^{4} \mathrm{~F}_{7 / 2},{ }^{4} \mathrm{~F}_{5 / 2},{ }^{4} \mathrm{~F}_{3 / 2},{ }^{2} \mathrm{G}_{9 / 2},{ }^{4} \mathrm{G}_{11 / 2},{ }^{4} \mathrm{G}_{9 / 2}$ and ${ }^{2} \mathrm{~K}_{15 / 2}$ excited states of $\mathrm{Er}^{3+}$. The observed Stark splitting is due to the semicrystalline nature of the investigated Er-doped sample. The inset shows an XRD pattern for the Er-doped sample, which reveals two broad bands typical of amorphous state, and narrow diffraction lines characteristic of crystalline phase. These peaks were identified as the $\mathrm{GaPO}_{4}$ crystalline phase (PDF card No. 00-031-0546). This is in a good agreement with the results obtained for glass in the following chemical composition: $30 \mathrm{Ga}_{2} \mathrm{O}_{3}-20 \mathrm{PbO}-50 \mathrm{P}_{2} \mathrm{O}_{5}$ (in $\mathrm{mol} \%$ ), where $\mathrm{GaPO}_{4}$ crystalline phase was also identified [59].

\subsection{Luminescence}

Luminescence spectra of rare earth ions in lead phosphate glasses were detected in the visible $\left(\mathrm{Eu}^{3+}, \mathrm{Tb}^{3+}\right)$ and near infrared $\left(\mathrm{Er}^{3+}\right)$ ranges. Figure 4 presents visible luminescence spectra for $\mathrm{Eu}^{3+}$ and $\mathrm{Tb}^{3+}$ ions in lead phosphate glasses. Luminescence spectrum of $\mathrm{Eu}^{3+}$ ions in lead phosphate glass was registered upon excitation of ${ }^{5} \mathrm{~L}_{6}$ state $\left(\lambda_{\text {ext }}=393 \mathrm{~nm}\right)$. Owing to small energy gaps between ${ }^{5} \mathrm{~L}_{6}$, ${ }^{5} \mathrm{D}_{2},{ }^{5} \mathrm{D}_{1}$ and ${ }^{5} \mathrm{D}_{0}$ states, the excitation energy transfers nonradiative very fast to the ${ }^{5} \mathrm{D}_{0}$ state. Next, visible emission corresponding to the ${ }^{5} \mathrm{D}_{0^{-}}{ }^{7} \mathrm{~F}_{\mathrm{J}}(\mathrm{J}=0,1,2,4)$ transitions of $\mathrm{Eu}^{3+}$ ions in lead phosphate glass is observed. The main red luminescence band at about $611 \mathrm{~nm}$ corresponds to ${ }^{5} \mathrm{D}_{0}{ }^{7} \mathrm{~F}_{2}$ transition of $\mathrm{Eu}^{3+}$. The ratio of integrated emission intensity of the ${ }^{5} \mathrm{D}_{0}-{ }^{7} \mathrm{~F}_{2}$ transition to the ${ }^{5} \mathrm{D}_{0}-{ }^{7} \mathrm{~F}_{1}$ transition, defined as red-to-orange fluorescence intensity ratio $\mathrm{R} / \mathrm{O}$ (and usually referred as $\mathrm{R}$ factor), is relative to the strength of covalent/ionic bonding between the $\mathrm{Eu}^{3+}$ ions and the surrounding ligands. The ${ }^{5} \mathrm{D}_{0}-{ }^{7} \mathrm{~F}_{1}$ transition is a magnetic-dipole transition, which is independent of the local symmetry. Therefore, the intensity ratio of the ${ }^{5} \mathrm{D}_{0}-{ }^{7} \mathrm{~F}_{2}$ transition to the ${ }^{5} \mathrm{D}_{0}{ }^{-}{ }^{7} \mathrm{~F}_{1}$ transition is the spectroscopic key to estimate the deviation from the site symmetries of $\mathrm{Eu}^{3+}$ ions. This ratio is a sensitive function of covalency and asymmetry around $\mathrm{Eu}^{3+}$ ions. Small $\mathrm{R}$ value is usually attributed to higher local symmetry of $\mathrm{Eu}^{3+}$ ions. The increase in $R$ value is due to increasing asymmetry. The red-to-orange luminescence intensity ratio $\mathrm{R}$ of $\mathrm{Eu}^{3+}$ ion in lead phosphate glass is close to 2.41 [45]. Furthermore, luminescence spectrum for 


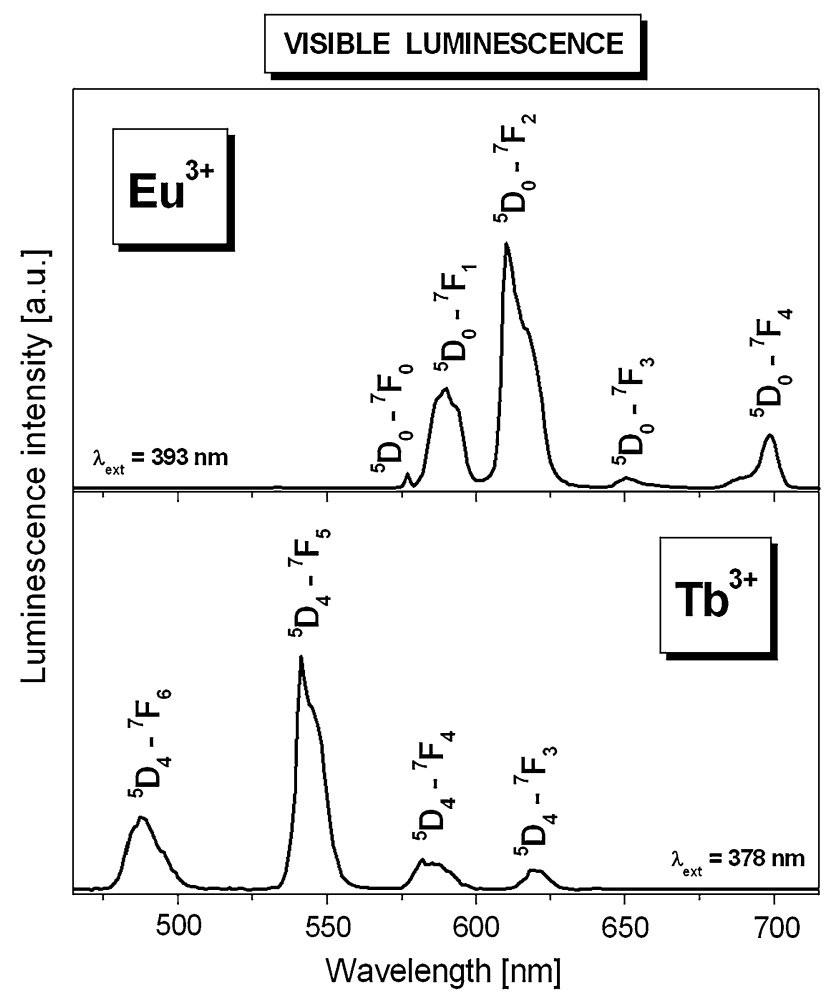

Fig. 4 Visible luminescence for $\mathrm{Eu}^{3+}$ and $\mathrm{Tb}^{3+}$ ions in lead phosphate glasses. Main red and green luminescence bands correspond to ${ }^{5} \mathrm{D}_{0}-{ }^{7} \mathrm{~F}_{2}\left(\mathrm{Eu}^{3+}\right)$ and ${ }^{5} \mathrm{D}_{4}-{ }^{7} \mathrm{~F}_{5}\left(\mathrm{~Tb}^{3+}\right)$ transitions of rare earth ions

$\mathrm{Tb}^{3+}$ ions was recorded under excitation by $378-\mathrm{nm}$ line. Several luminescence bands are observed in the wide spectral region, which correspond to the ${ }^{5} \mathrm{D}_{4-}{ }^{7} \mathrm{~F}_{\mathrm{J}}(\mathrm{J}=3,4$, $5,6)$ transitions of $\mathrm{Tb}^{3+}$ ions. The main green luminescence band located at $543 \mathrm{~nm}$ is related to ${ }^{5} \mathrm{D}_{4}-{ }^{7} \mathrm{~F}_{5}$ transition of $\mathrm{Tb}^{3+}$. The ratio of integrated emission intensity of the ${ }^{5} \mathrm{D}_{4-}{ }^{7} \mathrm{~F}_{5}$ transition (green line) to the ${ }^{5} \mathrm{D}_{4}{ }^{-} \mathrm{F}_{6}$ transition (blue line) allows determination of green-to-blue fluorescence factor $(\mathrm{G} / \mathrm{B})$. The $\mathrm{G} / \mathrm{B}\left(\mathrm{Tb}^{3+}\right)$ factor could play the same role as the $\mathrm{R}\left(\mathrm{Eu}^{3+}\right)$ factor and also describe the asymmetry of the local environment around the optically active dopant and covalent/ionic bonding between $\mathrm{Tb}^{3+}$ and $\mathrm{O}^{2-}$. Therefore, $\mathrm{Tb}^{3+}$ ions could be also used as spectroscopic probe similarly to europium ions. Calculated $\mathrm{G} / \mathrm{B}$ factor for $\mathrm{Tb}^{3+}$ ions in lead phosphate glass is equal to 3.09.

From accumulated experience, it is well known that the luminescence intensity is considered to be dependent on the glass host lattice through the crystal field. The optical radiation of rare earth ions is associated mainly with the forced electric-dipole transition. Thus, luminescence spectra of rare earths and their relative band intensities are dependent on the symmetry and strength of crystal field. It was pointed out that the luminescence intensity of ${ }^{5} \mathrm{D}_{4}-{ }^{7} \mathrm{~F}_{3}$ transition can become comparable to that of the main green

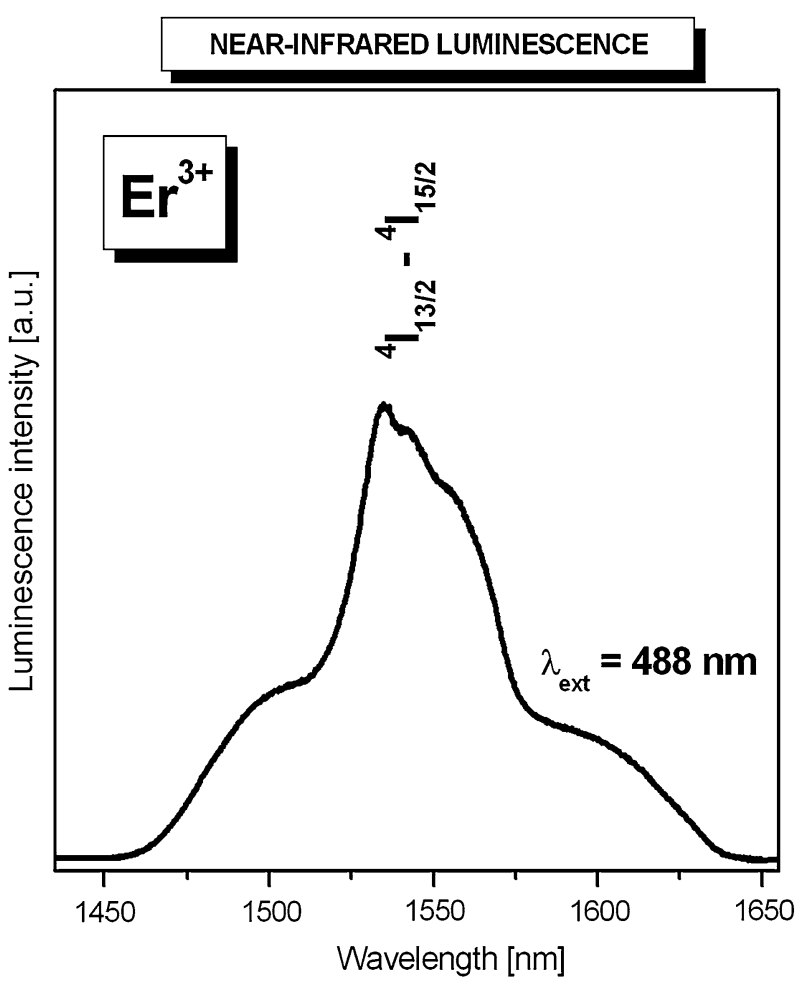

Fig. 5 Near-infrared luminescence of $\mathrm{Er}^{3+}$ ions in lead phosphate glass corresponding to the main ${ }^{4} \mathrm{I}_{13 / 2}-{ }^{4} \mathrm{I}_{15 / 2}$ laser transition

${ }^{5} \mathrm{D}_{4}{ }^{-}{ }^{7} \mathrm{~F}_{5}$ transition of $\mathrm{Tb}^{3+}$, when the crystal field is very strong. It was observed for $\mathrm{Tb}^{3+}$-doped borosilicate glass samples calcined at $1,000{ }^{\circ} \mathrm{C}$ [60]. In our case, the luminescence intensity is much higher for the ${ }^{5} \mathrm{D}_{4}-{ }^{7} \mathrm{~F}_{5}$ transition than for the ${ }^{5} \mathrm{D}_{4}{ }^{7} \mathrm{~F}_{3}$ transition of $\mathrm{Tb}^{3+}$, indicating low strength of the crystal field. Moreover, the higher values of $\mathrm{G} / \mathrm{B}\left(\mathrm{Tb}^{3+}\right)$ and $\mathrm{R}\left(\mathrm{Eu}^{3+}\right)$ suggest a higher distortion of site symmetry and a degree of covalence between rare earth and oxygen ions. Our investigations indicate that both $\mathrm{G} / \mathrm{B}$ $\left(\mathrm{Tb}^{3+}\right)$ and $\mathrm{R}\left(\mathrm{Eu}^{3+}\right)$ values obtained for lead phosphate glass are rather high, which suggests a large distortion of local symmetry and a more covalent character of the bonding between rare earth and oxygen ions. This is due to the presence of heavy metal oxide $(\mathrm{PbO})$ in glass composition. Further spectroscopic investigations indicate that the luminescence band assigned to the magnetic-dipole ${ }^{5} \mathrm{D}_{0}-{ }^{7} \mathrm{~F}_{1}$ transition of $\mathrm{Eu}^{3+}$ ions in lead phosphate glass is well resolved into three Stark components. The existence of three overlapping peaks for ${ }^{5} \mathrm{D}_{0}{ }^{-7} \mathrm{~F}_{1}$ transition indicates low symmetry (orthorhombic, triclinic or monoclinic) of $\mathrm{Eu}^{3+}$ environments. This is also in a good agreement with the previously published results for $\mathrm{Eu}^{3+}$ ions in lead borate glass systems, which were examined using the fluorescence line narrowing (FLN) technique [61].

Finally, near-infrared luminescence spectrum for $\mathrm{Er}^{3+}$ ions in lead phosphate glass was recorded under excitation by $488-n m$ line (Fig. 5). The excitation energy transfers 
Table 2 Spectroscopic parameters $(\Delta \lambda, \tau)$ for $\mathrm{Er}^{3+}$ ions in phosphate-based glasses

\begin{tabular}{|c|c|c|c|c|}
\hline Phosphate-based glass host & $\lambda(\mathrm{nm})$ & $\Delta \lambda(\mathrm{nm})$ & $\tau(\mathrm{ms})$ & Ref. \\
\hline $19 \mathrm{NaF}-38 \mathrm{RF}_{2}-30 \mathrm{AlF}_{3}-5 \mathrm{YF}_{3}-4 \mathrm{Al}\left(\mathrm{PO}_{3}\right)_{3}-4 \mathrm{ErF}_{3}(\mathrm{R}=\mathrm{Mg}, \mathrm{Ca}, \mathrm{Sr}, \mathrm{Ba})$ & 1,530 & 56 & 7.36 & 31 \\
\hline $\operatorname{EDLP}_{x}(x=1-4)$ & 1,530 & $27-40$ & $0.63-2.75$ & 38 \\
\hline $20 \mathrm{Na}_{2} \mathrm{O}-40 \mathrm{PbCl}_{2}-40 \mathrm{P}_{2} \mathrm{O}_{5}$ & 1,540 & $40-60$ & $2.13-2.5$ & 70 \\
\hline 92NAP- $(8-x) \mathrm{Al}_{2} \mathrm{O}_{3}-(\mathrm{x}) \mathrm{Er}_{2} \mathrm{O}_{3}$ & 1,530 & $52-57$ & $0.97-7.86$ & 71 \\
\hline $64 \mathrm{P}_{2} \mathrm{O}_{5}-12 \mathrm{Al}_{2} \mathrm{O}_{3}-3,5\left(\mathrm{Er}_{2} \mathrm{O}_{3}+\mathrm{La}_{2} \mathrm{O}_{3}\right)-20,5 \mathrm{MO}(\mathrm{M}=\mathrm{Mg}, \mathrm{Ca}, \mathrm{Ba})$ & 1,537 & 55 & $\begin{array}{l}7.9 \text { (glass) } \\
2.8 \text { (glass fiber) }\end{array}$ & 72 \\
\hline $40 \mathrm{MgF}_{2}-40 \mathrm{BaF}_{2}-10 \mathrm{Ba}\left(\mathrm{PO}_{3}\right)_{2}-10 \mathrm{Al}\left(\mathrm{PO}_{3}\right)_{3}$ & 1,536 & 91 & - & 73 \\
\hline $20 \mathrm{Bi}\left(\mathrm{PO}_{3}\right)_{3}-10 \mathrm{Ba}\left(\mathrm{PO}_{3}\right)_{2}-35 \mathrm{BaF}_{2}-35 \mathrm{MgF}_{2}$ & 1,516 & 64 & - & \\
\hline $67 \mathrm{P}_{2} \mathrm{O}_{5}-14 \mathrm{Al}_{2} \mathrm{O}_{3}-14 \mathrm{Li}_{2} \mathrm{O}-1 \mathrm{~K}_{2} \mathrm{O}-4\left(\mathrm{Yb}_{2} \mathrm{O}_{3}+\mathrm{Er}_{2} \mathrm{O}_{3}\right)$ & 1,535 & 55 & 7.9 & 74 \\
\hline Metaphosphate & - & 61 & 7.9 & 75 \\
\hline $24\left(\mathrm{NaPO}_{3}\right)_{6}-30 \mathrm{KH}_{2} \mathrm{PO}_{4}-25 \mathrm{TiO}_{2}-20 \mathrm{XCl}_{2}-1 \mathrm{Er}_{2} \mathrm{O}_{3}(\mathrm{X}=\mathrm{Mg}, \mathrm{Ca}, \mathrm{Sr})$ & 1,534 & $39-41$ & - & 76 \\
\hline $45 \mathrm{PbO}-45 \mathrm{P}_{2} \mathrm{O}_{5}-9.5 \mathrm{Ga}_{2} \mathrm{O}_{3}-0.5 \mathrm{Er}_{2} \mathrm{O}_{3}$ & 1,535 & 50 & 1.85 & This work \\
\hline
\end{tabular}

nonradiatively very quickly to the ${ }^{4} \mathrm{I}_{13 / 2}$ state due to small energy gaps between the ${ }^{4} \mathrm{~S}_{3 / 2}$ state and lower-lying excited states of $\mathrm{Er}^{3+}$. For that reason, we also observe very lowintensity green emission corresponding to ${ }^{4} \mathrm{~S}_{3 / 2}-{ }^{4} \mathrm{I}_{15 / 2}$ transitions of $\mathrm{Er}^{3+}$ ions in lead phosphate glass [62]. The observed near-infrared luminescence at about $1.5 \mu \mathrm{m}$ corresponds to ${ }^{4} \mathrm{I}_{13 / 2}-{ }^{4} \mathrm{I}_{15 / 2}$ laser transition of $\mathrm{Er}^{3+}$, which is demanded for optical amplifiers operating in the third telecommunication window [5-8, 63-70]. Several spectroscopic parameters of $\mathrm{Er}^{3+}$ ions are important in relation to practical application in optoelectronics. Two of them, luminescence linewidth and lifetime, are determined from emission spectrum and its decay. The luminescence decay curves for rare earth $\left(\mathrm{Eu}^{3+}, \mathrm{Tb}^{3+}\right.$ and $\left.\mathrm{Er}^{3+}\right)$ ions in lead phosphate glasses will be examined in the next section. The spectral linewidth $\Delta \lambda$ defined as full width in half maximum (FWHM) is a very important parameter for tunable broadband NIR laser systems, whereas the relatively long luminescence lifetime $\tau$ of the metastable level required for the high population inversion is the critical factor in the success of Er-doped fiber amplifiers (EDFA) in optical communications. Both parameters $\Delta \lambda$ and $\tau$ for $\mathrm{Er}^{3+}$ ions in lead phosphate glass are close to $50 \mathrm{~nm}$ and $1.85 \mathrm{~ms}$, respectively. They are given in Table 2 in comparison with values obtained for other oxide and oxyhalide phosphatebased glasses [31, 38, 70-76].

\subsection{Luminescence decay analysis}

Luminescence decay curves from the excited states of $\mathrm{Tb}^{3+}$, $\mathrm{Eu}^{3+}$ and $\mathrm{Er}^{3+}$ ions in lead phosphate glasses have been analyzed in detail. Figure 6 shows luminescence decay curves from the ${ }^{5} \mathrm{D}_{4}\left(\mathrm{~Tb}^{3+}\right),{ }^{5} \mathrm{D}_{0}\left(\mathrm{Eu}^{3+}\right)$ and ${ }^{4} \mathrm{I}_{13 / 2}\left(\mathrm{Er}^{3+}\right)$ excited states. All decay curves become nearly exponential due to the lack of energy transfer between rare earth ions. The luminescence lifetimes for ${ }^{5} \mathrm{D}_{4},{ }^{5} \mathrm{D}_{0}$ and ${ }^{4} \mathrm{I}_{13 / 2}$ states of rare

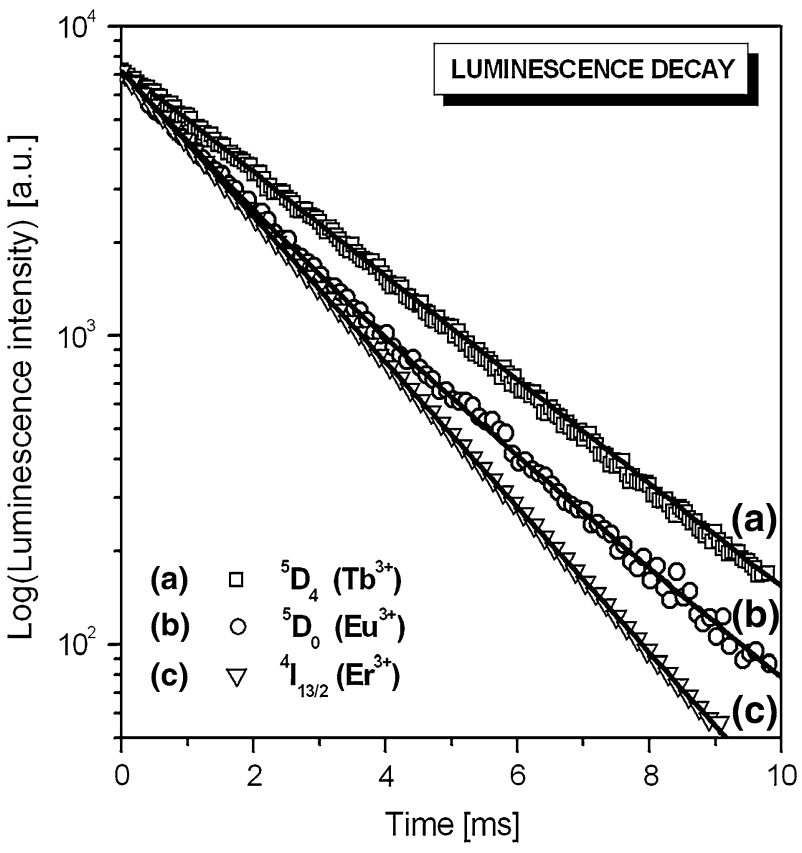

Fig. 6 Luminescence decay curves for the excited states of $\mathrm{Tb}^{3+}$, $\mathrm{Eu}^{3+}$ and $\mathrm{Er}^{3+}$ ions in lead phosphate glasses

earth ions in lead phosphate glass are close to $2.65 \mathrm{~ms}$ $\left(\mathrm{Tb}^{3+}\right), 2.02 \mathrm{~ms}\left(\mathrm{Eu}^{3+}\right)$ and $1.85 \mathrm{~ms}\left(\mathrm{Er}^{3+}\right)$, respectively.

In order to estimate ion-ion interaction, the InokutiHirayama model [77] has been applied for luminescence decay curve analysis. The time evolution of the $\mathrm{Ln}^{3+}$ $(\mathrm{Ln}=\mathrm{Tb}, \mathrm{Eu} \mathrm{Er})$ luminescence intensity was fitted to that predicted by the formula:

$I(t)=A \exp \left[-\left(\frac{t}{\tau_{m}}\right)-\alpha\left(\frac{t}{\tau_{m}}\right)^{3 / s}\right]$

where $A$ is a constant, $I(t)$ is luminescence intensity after pulse excitation, $\tau_{m}$ is the intrinsic lifetime of donors in the 
absence of acceptors, $s=6$ for a dipole-dipole interaction between the ions, and $\alpha$ is the parameter given by the relation:

$\alpha=\frac{4}{3} \pi \Gamma(1-3 / s) N_{A} R_{0}^{3}$

where $\Gamma$ is the Euler function, $N_{A}$ is the concentration of acceptor ions, and $R_{O}$ is the critical transfer distance defined as a donor-acceptor separation for which the rate of energy transfer between a donor-acceptor is equal to the rate of intrinsic decay rate $\tau_{m}^{-1}$.

The donor-acceptor interaction parameter $C_{D-A}$ is calculated using the following relation:

$C_{D-A}=\frac{R_{0}^{6}}{\tau_{m}}$

Results of the fitting procedure using the Inokuti-Hirayama model are given in Table 3.

The critical transfer distance $R_{0}$ varies nearly from 4 to $8 \AA$, and its value is similar to that obtained from ${ }^{31} \mathrm{P}$ MAS NMR, X-ray and neutron diffraction measurements, which were carried out for phosphate glasses containing rare earth ions [78-82]. Three main types of Ln-Ln separation related to (1) $\mathrm{Ln}-\mathrm{O}-\mathrm{Ln}$ configuration as found in orthorhombic metaphosphate crystals in the range 3.9-4.3 $\AA$ (the Ln-Ln ion clustering must be present), (2) V-shaped Ln-(OPO)Ln configuration as found in ultraphosphate and monoclinic metaphosphate crystals in the range 5.2-5.7 $\AA$ and (3) approximately linear $\mathrm{Ln}-(\mathrm{OPO})-\mathrm{Ln}$ configuration as found in orthorhombic metaphosphate crystals in the range 5.5-7 $\AA$ can be present in Ln-doped phosphate-based glasses. It was discussed based on direct observation of $\mathrm{Ln}-\mathrm{Ln}$ distances in rare earth-doped phosphate glasses by magnetic difference neutron diffraction [83].

Finally, the donor-acceptor interaction parameter $C_{D-A}$ was used to calculate the energy transfer probability $W_{D-A}$ using the following relation:

$W_{D-A}=\frac{C_{D-A}}{R_{0}^{6}}$

Table 3 Results of the fitting of the luminescence decay curves from ${ }^{5} \mathrm{D}_{4}\left(\mathrm{~Tb}^{3+}\right),{ }^{5} \mathrm{D}_{0}\left(\mathrm{Eu}^{3+}\right)$ and ${ }^{4} \mathrm{I}_{13 / 2}\left(\mathrm{Er}^{3+}\right)$ excited states of rare earth ions in lead phosphate glass obtained using the Inokuti-Hirayama model

\begin{tabular}{llll}
\hline Parameters & $\mathrm{Tb}^{3+}\left({ }^{5} \mathrm{D}_{4}\right)$ & $\mathrm{Eu}^{3+}\left({ }^{5} \mathrm{D}_{0}\right)$ & $\mathrm{Er}^{3+}\left({ }^{4} \mathrm{I}_{13 / 2}\right)$ \\
\hline $\mathrm{N}_{\mathrm{A}}\left(10^{20}\right.$ ion $\left.\mathrm{cm}^{-3}\right)$ & 1.52 & 1.57 & 1.45 \\
$\alpha$ & 0.1 & 0.6 & 0.07 \\
$\mathrm{R}_{0}(\AA)$ & 5.62 & 8.02 & 4.02 \\
$\mathrm{C}_{\mathrm{D}-\mathrm{A}}\left(10^{-41} \mathrm{~cm}^{6} \mathrm{~s}^{-1}\right)$ & 1.22 & 13.2 & 0.23
\end{tabular}

The molar ion concentrations $N_{A}, \alpha$ values, the critical transfer distances $R_{0}$ and the donor-acceptor interaction parameters $C_{D-A}$ are reported
The results including $W_{D-A}$ parameters together with the measured luminescence lifetimes and energy gaps between excited states and lower-lying states of rare earth ions are given in Table 4.

Generally, the energy transfer probabilities for the $\mathrm{Eu}^{3+}$ $\left({ }^{5} \mathrm{D}_{0}\right), \mathrm{Tb}^{3+}\left({ }^{5} \mathrm{D}_{4}\right)$ and $\mathrm{Er}^{3+}\left({ }^{4} \mathrm{I}_{13 / 2}\right)$ are similar to the value $\left(W_{D-A}=375 \mathrm{~s}^{-1}\right)$, which was calculated using relation (4) and some following parameters $\left(R_{0}=7.12 \AA\right.$; $\tau=2.04 \mathrm{~ms} ; \mathrm{C}_{\mathrm{D}-\mathrm{A}}=4.88 \times 10^{-41} \mathrm{~cm}^{6} \mathrm{~s}^{-1}$ ) obtained for $\mathrm{Sm}^{3+}$ ions $(0.5 \mathrm{~mol} \%)$ in lead fluorophosphate glasses [44]. The smaller $W_{D-A}$ parameters indicate low selfquenching luminescence of rare earths. Our results clearly indicate that luminescence lifetime of the excited state of $\mathrm{Ln}^{3+}$ increases, whereas the energy transfer probability for $\mathrm{Ln}^{3+}$ reduces with increasing separation energy between

Table 4 Results of the fitting of the luminescence decay curves from ${ }^{5} \mathrm{D}_{4}\left(\mathrm{~Tb}^{3+}\right),{ }^{5} \mathrm{D}_{0}\left(\mathrm{Eu}^{3+}\right)$ and ${ }^{4} \mathrm{I}_{13 / 2}\left(\mathrm{Er}^{3+}\right)$ excited states of rare earth ions in lead phosphate glass obtained using the Inokuti-Hirayama model

\begin{tabular}{llll}
\hline Parameters & $\mathrm{Tb}^{3+}\left({ }^{5} \mathrm{D}_{4}\right)$ & $\mathrm{Eu}^{3+}\left({ }^{5} \mathrm{D}_{0}\right)$ & $\mathrm{Er}^{3+}\left({ }^{4} \mathrm{I}_{13 / 2}\right)$ \\
\hline$\Delta E^{\mathrm{a}}\left(\mathrm{cm}^{-1}\right)$ & 15,000 & 12,500 & 6,600 \\
$\tau_{m}(\mathrm{~ms})$ & 2.65 & 2.02 & 1.85 \\
$W_{D-A}\left(\mathrm{~s}^{-1}\right)$ & 387 & 496 & 540
\end{tabular}

The energy gaps $\Delta E$ between excited states and low-lying states of rare earth ions, the measured luminescence lifetimes $\tau_{m}$ and the energy transfer probabilities $W_{D-A}$ are reported

${ }^{\text {a }}$ Energy gap between excited state and low-lying state of rare earth ion (see Fig. 7)

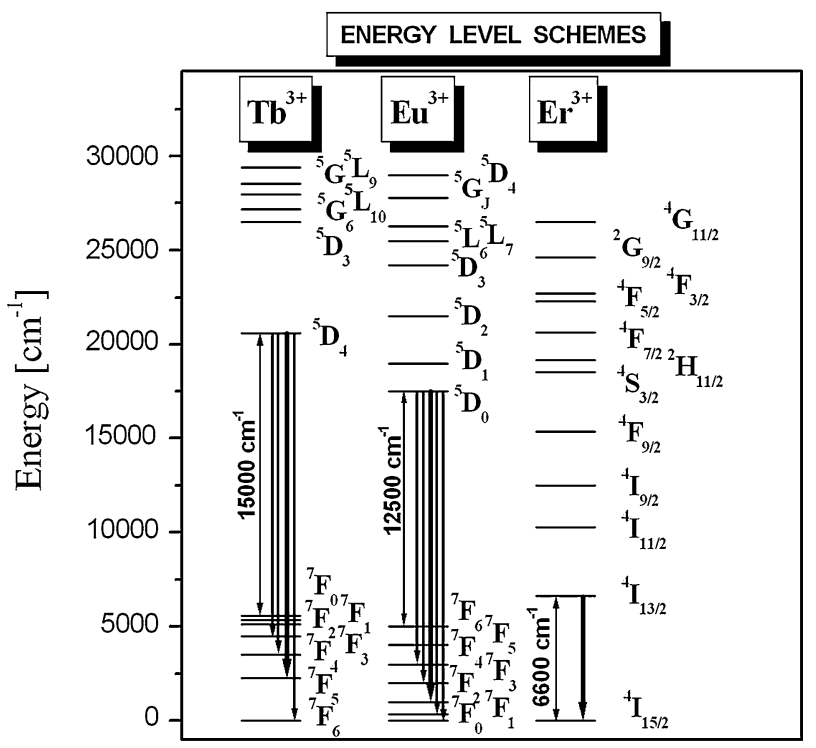

Fig. 7 Energy-level schemes for $\mathrm{Tb}^{3+}, \mathrm{Eu}^{3+}$ and $\mathrm{Er}^{3+}$ ions in lead phosphate glasses. The main green $\left(\mathrm{Tb}^{3+}\right)$, red $\left(\mathrm{Eu}^{3+}\right)$ and NIR $\left(\mathrm{Er}^{3+}\right)$ transitions are indicated (in bold). The energy gaps between the excited state and low-lying state of rare earth ions are also presented 
excited state and lower-lying state of $\mathrm{Ln}^{3+}$ ions in $\mathrm{Er}^{3+} \rightarrow \mathrm{Eu}^{3+} \rightarrow \mathrm{Tb}^{3+}$ direction (Table 4). The energy separations for $\mathrm{Tb}^{3+}, \mathrm{Eu}^{3+}$ and $\mathrm{Er}^{3+}$ ions are also demonstrated on the energy-level schemes (Fig. 7). From the emission spectra and their decays as well as the $\mathrm{Ln}^{3+}-\mathrm{Ln}^{3+}$ interaction calculations, it can be concluded that lead phosphate glasses containing rare earth ions are promising materials emitting visible light $\left(\mathrm{Eu}^{3+}, \mathrm{Tb}^{3+}\right)$ or nearinfrared radiation $\left(\mathrm{Er}^{3+}\right)$.

\section{Conclusions}

Excitation and luminescence properties of rare earth ions in lead phosphate glasses have been studied. The optically active rare earth ions were limited to $\mathrm{Eu}^{3+}, \mathrm{Tb}^{3+}$ and $\mathrm{Er}^{3+}$. Several registered excitation and luminescence bands correspond to well-known lines characteristic for $4 f^{6}-4 f^{6}\left(\mathrm{Eu}^{3+}\right), 4 f^{8}-4 f^{8}\left(\mathrm{~Tb}^{3+}\right)$ and $4 f^{11}-4 f^{11}\left(\mathrm{Er}^{3+}\right)$ electronic transitions of trivalent rare earths. From excitation spectra of $\mathrm{Eu}^{3+}$ ions, the electron-phonon coupling strength and phonon energy of the glass host were calculated and compared to that obtained by Raman spectrum. Several narrowed and well-resolved excitation and emission bands for $\mathrm{Er}^{3+}$ ions prove the semicrystalline nature of the studied Er-doped sample. This was confirmed by XRD. Some spectroscopic parameters such as luminescence peak wavelength, linewidth and measured lifetime were determined based on luminescence spectra and their decays. Main intense and long-lived luminescence bands correspond to the ${ }^{5} \mathrm{D}_{0}-{ }^{7} \mathrm{~F}_{2}$ (red) transition of $\mathrm{Eu}^{3+}$, the ${ }^{5} \mathrm{D}_{4-}{ }^{7} \mathrm{~F}_{5}$ (green) transition of $\mathrm{Tb}^{3+}$ and the ${ }^{4} \mathrm{I}_{13 / 2}-{ }^{4} \mathrm{I}_{15 / 2}$ (near-infrared) transition of $\mathrm{Er}^{3+}$. In particular, two spectroscopic parameters, the luminescence linewidth and measured lifetime, were analyzed for the latter main NIR laser transition of $\mathrm{Er}^{3+}$, which is demanded for broadband optical amplifiers operating in the third telecommunication window. The red-to-orange $\left(\mathrm{Eu}^{3+}\right)$ and green-to-blue $\left(\mathrm{Tb}^{3+}\right)$ luminescence intensity ratios were also determined.

Theoretical calculations based on the Inokuti-Hirayama model were applied for luminescence decay curve analysis in order to obtain information about interactions between rare earth ions. Some parameters such as the critical transfer distances, the donor-acceptor interaction parameters and the energy transfer probabilities were calculated using the fitting of the luminescence decay curves from ${ }^{5} \mathrm{D}_{0}$ $\left(\mathrm{Eu}^{3+}\right),{ }^{5} \mathrm{D}_{4}\left(\mathrm{~Tb}^{3+}\right)$ and ${ }^{4} \mathrm{I}_{13 / 2}\left(\mathrm{Er}^{3+}\right)$ excited states of rare earth ions in lead phosphate glass. The energy transfer probabilities for $\mathrm{Eu}^{3+}\left({ }^{5} \mathrm{D}_{0}\right), \mathrm{Tb}^{3+}\left({ }^{5} \mathrm{D}_{4}\right)$ and $\mathrm{Er}^{3+}\left({ }^{4} \mathrm{I}_{13 / 2}\right)$ are relatively small, which indicates low self-quenching luminescence of rare earth ions in lead phosphate glasses. It suggests that lead phosphate glass hosts are promising solid-state materials for rare earth luminescence in the visible and near-infrared spectral region.

Acknowledgments The National Science Centre (Poland) supported this work under research project 2011/01/B/ST5/00978. The author Marta Sołtys received grant from the project "DoktoRISScholarship program for innovative Silesia" cofinanced by the European Union under the European Social Fund.

Open Access This article is distributed under the terms of the Creative Commons Attribution License which permits any use, distribution, and reproduction in any medium, provided the original author(s) and the source are credited.

\section{References}

1. L.J. Borrero-González, I.A.A. Terra, L.A.O. Nunes, A.M. Farias, M.J. Barboza, J.H. Rohling, A.N. Medina, M.L. Baesso, Appl. Phys. B 107, 415 (2012)

2. M. Jiménez de Castro, J.M. Fernández Navarro, Appl. Phys. B 106, 669 (2012)

3. V. Venkatramu, R. Vijaya, S.F. León-Luis, P. Babu, C.K. Jayasankar, V. Lavín, L.J. Dhareshwar, J. Alloys Compd. 509, 5084 (2011)

4. Q. Zhang, G. Chen, G. Zhang, J. Qiu, D. Chen, J. Appl. Phys. 107, $023102(2010)$

5. Y. Ding, S. Jiang, B-Ch. Hwang, T. Luo, N. Peyghambarian, Y. Himei, T. Ito, Y. Miura, Opt. Mater. 15, 123 (2000)

6. H. Yamauchi, Y. Ohishim, Opt. Mater. 27, 679 (2005)

7. Y. Luo, J. Zhang, S. Lu, X. Wang, J. Lumin. 122-123, 967 (2007)

8. W.A. Pisarski, J. Pisarska, R. Lisiecki, Ł. Grobelny, G. Dominiak-Dzik, W. Ryba-Romanowski, Chem. Phys. Lett. 472, 217 (2009)

9. Z. Pan, S.H. Morgan, A. Loper, V. King, B.H. Long, W.E. Collins, J. Appl. Phys. 77, 4688 (1995)

10. F. Lahoz, P. Haro-Gonzalez, F. Rivera-López, S. González-Pérez, I.R. Martín, N.E. Capuj, C.N. Afonso, C.N. Afonso, J. Gonzalo, J. Fernández, R. Balda, Appl. Phys. A 93, 621 (2008)

11. L.R.P. Kassab, F.A. Bomfim, J.R. Martinelli, N.U. Wetter, J.J. Neto, C.B. de Araújo, Appl. Phys. B 94, 239 (2009)

12. S.F. León-Luis, U.R. Rodríguez-Mendoza, P. Haro-González, I.R. Martín, V. Lavín, Sens. Actuat. B 174, 176 (2012)

13. S. Fuchi, A. Sakano, R. Mizutani, Y. Takeda, Appl. Phys. B 105, 877 (2011)

14. Z. Pan, S.H. Morgan, K. Dyer, A. Ueda, H. Liu, J. Appl. Phys. 79, $8906(1996)$

15. Z. Duan, J. Zhang, L. Hu, J. Appl. Phys. 101, 043110 (2007)

16. S. Babu, K. Jang, E.J. Cho, H. Lee, C.K. Jayasankar, J. Phys. D Appl. Phys. 40, 5767 (2007)

17. X. Qiao, X. Fan, M. Wang, X. Zhang, J. Phys. D Appl. Phys. 42, 055103 (2009)

18. X.P. Jiang, Z.M. Yang, T. Liu, S.H. Xu, J. Appl. Phys. 105, $103113(2009)$

19. P. Ghigna, C. Tomasi, A. Speghini, M. Bettinelli, M. Scavini, J. Appl. Phys. 105, 023519 (2009)

20. T. Som, B. Karmakar, J. Phys. Condens. Matter 42, 035603 (2010)

21. R.R. Xu, Y. Tian, M. Wang, L.L. Hu, J.J. Zhang, Appl. Phys. B 102, 109 (2011)

22. D. Wei, B. Yuan, Y. Huang, T. Tsuboi, H.J. Seo, J. Am. Ceram. Soc. 96, 2167 (2013)

23. Y. Guan, Z. Wei, Y. Huang, R. Maalej, H.J. Seo, Ceram. Int. 39, $7023(2013)$ 
24. R. Balda, J. Fernandez, J.L. Adam, M.A. Arriandiaga, Phys. Rev. B 54, 12076 (1996)

25. R. Van Deun, K. Binnemans, C. Gorller-Walrand, J.L. Adam, J. Phys.: Condens. Matter 10, 7231 (1998)

26. R. Praveena, R. Vijaya, C.K. Jayasankar, Spectrochim. Acta A 70, 577 (2008)

27. S. Babu, P. Babu, C.K. Jayasankar, Th Tröster, W. Sievers, G. Wortmann, Opt. Mater. 31, 624 (2009)

28. Ch. Basavapoornima, C.K. Jayasankar, P.P. Chandrachoodan, Physica B 404, 235 (2009)

29. K. Linganna, C.K. Jayasankar, Spectrochim. Acta A 97, 788 (2012)

30. V.B. Sreedhar, D. Ramachari, C.K. Jayasankar, Physica B 408, 158 (2013)

31. M. Liao, L. Hu, Z. Duan, L. Zhang, L. Wen, Appl. Phys. B 86, 83 (2007)

32. Y. Tian, L.Y. Zhang, R.R. Xu, L.L. Hu, J.J. Zhang, Appl. Phys. B 101, 861 (2010)

33. Y. Tian, R. Xu, L. Zhang, L. Hu, J. Zhang, J. Appl. Phys. 108, 083504 (2010)

34. T.B. Brito, M.V.D. Vermelho, E.A. Gouveia, M.T. de Araujo, I. Guedes, C.-K. Loong, L.A. Boatner, J. Appl. Phys. 102, 043113 (2007)

35. E.A.F. Santos, W.F. Silva, M.T. de Araújo, M.V.D. Vermelho, I. Guedes, C.-K. Loong, L.A. Boatner, C. Jacinto, J. Appl. Phys. 106, 113111 (2009)

36. C.C. Santos, U. Rocha, I. Guedes, M.V.D. Vermelho, L.A. Boatner, C. Jacinto, J. Appl. Phys. 111, 123101 (2012)

37. C.C. Santos, I. Guedes, J.P. Siqueira, L. Misoguti, S.C. Zilio, L.A. Boatner, Appl. Phys. B 99, 559 (2010)

38. C.C. Santos, I. Guedes, C.-K. Loong, L.A. Boatner, A.L. Moura, M.T. de Arauj, C. Jacinto, M.V.D. Vermelho, J. Phys. D Appl. Phys. 43, 025102 (2010)

39. Ch. Srinivasa Rao, K. Upendra Kumar, P. Babu, C.K. Jayasankar, Opt. Mater. 35, 102 (2012)

40. M. Sobczyk, P. Starynowicz, R. Lisiecki, W. Ryba-Romanowski, Opt. Mater. 30, 1571 (2008)

41. R. Praveena, V. Venkatramu, P. Babu, C.K. Jayasankar, Physica B 403, 3527 (2008)

42. R. Praveena, V. Venkatramu, P. Babu, C.K. Jayasankar, Th Tröster, W. Tröster, G. Wortmann, J. Phys.: Condens. Matter 21, 035108 (2009)

43. C.R. Kesavulu, C.K. Jayasankar, Mater. Chem. Phys. 130, 1078 (2011)

44. C.R. Kesavulu, C.K. Jayasankar, J. Lumin. 132, 2802 (2012)

45. W.A. Pisarski, L. Żur, J. Pisarska, Opt. Lett. 36, 990 (2011)

46. V.M. Churikov, A.I. Valeyev, K.O. Schavelev, O.S. Schavelev, Opt. Mater. 19, 415 (2002)

47. L.M. Deen, M.S. Al Salhi, M.M. Elkholy, J. Non-Cryst. Solids 354, 3762 (2008)

48. L. Zhang, M. Peng, G. Dong, J. Qiu, Opt. Mater. 34, 1202 (2012)

49. F. Rivera-López, P. Babu, L. Jyothi, U.R. Rodríguez-Mendoza, I.R. Martín, C.K. Jayasankar, V. Lavín, Opt. Mater. 34, 1235 (2012)

50. J. Pisarska, J. Phys.: Condens. Matter 21, 285101 (2009)

51. J. Pisarska, W.A. Pisarski, W. Ryba-Romanowski, Opt. Laser Technol. 42, 805 (2010)

52. Y. Yan, A.J. Faber, H. de Waal, J. Non-Cryst. Solids 181, 283 (1995)

53. C. Jacinto, S.L. Oliveira, L.A.O. Nunes, T. Catunda, M.J.V. Bell, J. Appl. Phys. 100, 113103 (2006)
54. I.A.A. Terra, A.S.S. de Camargo, L.A.O. Nunes, R.A. Carvalho, M.S. Li, J. Appl. Phys. 100, 123103 (2006)

55. X. Yu, F. Song, W. Wang, L. Luo, L. Han, Z. Cheng, T. Sun, J. Tian, E.Y.B. Pun, J. Appl. Phys. 104, 113105 (2008)

56. H. Ohkawa, H. Hayashi, Y. Kondo, Opt. Mater. 33, 128 (2010)

57. H. Ebendorff-Heidepriem, D. Ehrt, J. Non-Cryst. Solids 208, 205 (1996)

58. G. Vijaya Prakash, R. Jagannathan, Spectrochim. Acta A 55, 1799 (1999)

59. J. Schwarz, K. Vosejpkova, J. Therm. Anal. Calorim. 104, 1051 (2011)

60. K. Tonooka, O. Nishimura, J. Lumin. 87-89, 679 (2000)

61. V. Venkatramu, D. Navarro-Urios, P. Babu, C.K. Jayasankar, V. Lavin, J. Non-Cryst. Solids 351, 929 (2005)

62. J. Pisarska, L. Żur, T. Goryczka, W.A. Pisarski, J. Rare Earths 29, 1157 (2011)

63. S. Tanabe, C. R. Chimie 5, 815 (2002)

64. H. Lin, S. Jiang, J. Wu, F. Song, N. Peyghambarian, E.Y.B. Pun, J. Phys. D Appl. Phys. 36, 812 (2003)

65. R. Rolli, M. Montagna, S. Chaussedent, A. Monteil, V.K. Tikhomirov, M. Ferrari, Opt. Mater. 21, 743 (2003)

66. S. Hocde, S. Jiang, X. Peng, N. Peyghambarian, T. Luo, M. Morell, Opt. Mater. 25, 149 (2004)

67. S. Tanabe, J. Alloys Compd. 408-412, 675 (2006)

68. H. Lin, S. Tanabe, L. Lin, Y.Y. Hou, K. Liu, D.L. Yang, T.C. Ma, J.Y. Yu, E.Y.B. Pun, J. Lumin. 124, 167 (2007)

69. A. Amarnath Reddy, S. Surendra Babu, K. Pradeesh, C.J. Otton, G. Vijaya Prakash, J. Alloys Compd. 509, 4047 (2011)

70. K. Pradeesh, C.J. Oton, V.K. Agotiya, M. Raghavendra, G.V. Prakash, Opt. Mater. 31, 155 (2008)

71. A.A. Reddy, S.S. Babu, K. Pradeesh, C.J. Otton, G.V. Prakash, J. Alloy. Compd. 509, 4047 (2011)

72. S. Jiang, T. Luo, B. Hwang, F. Smekatala, K. Seneschal, J. Lucas, N. Peyghambarian, J. Non-Cryst. Solids 263/264, 364 (2000)

73. J.H. Choi, F.G. Shi, A. Margaryan, W. van der Veer, J. Alloy. Compd. 450, 540 (2008)

74. S. Jiang, M. Myers, N. Peyghambarian, J. Non-Cryst. Solids 239, 143 (1998)

75. P. Babu, H.J. Seo, K.H. Jang, R. Balakrishnaiah, C.K. Jayasankar, K.-S. Lim, V. Lavín, J. Opt. Soc. Am. B 24, 2218 (2007)

76. D.V.R. Murthy, A.M. Babu, B.C. Jamalaiah, L.R. Moorthy, M. Jayasimhadri, K. Jang, H.S. Lee, S.S. Yi, J.H. Jeong, J. Alloy. Compd. 491, 349 (2010)

77. M. Inokuti, F. Hirayama, J. Chem. Phys. 43, 1978 (1965)

78. J.M. Cole, E.R.H. van Eck, G. Mountjoy, R.J. Newport, T. Brennan, G.A. Saunders, J. Phys.: Condens. Matter 11, 9165 (1999)

79. J.M. Cole, E.R.H. van Eck, G. Mountjoy, R. Anderson, T. Brennan, G. Bushnell-Wye, R.J. Newport, G.A. Saunders, J. Phys.: Condens. Matter 13, 4105 (2001)

80. J.M. Cole, A.C. Wright, R.J. Newport, R.N. Sinclair, H.E. Fischer, G.J. Cuello, R.A. Martin, J. Phys.: Condens. Matter 19, 056002 (2007)

81. R.A. Martin, P.S. Salmon, H.E. Fischer, G.J. Cuello, J. Phys.: Condens. Matter 15, 8235 (2003)

82. R.A. Martin, P.S. Salmon, H.E. Fischer, G.J. Cuello, Phys. Rev. Lett. 90, 185501 (2003)

83. J.M. Cole, A.C. Hannon, R.A. Martin, R.J. Newport, Phys. Rev. B 73, 104210 (2006) 